\title{
Approaching Sustainable Energy Management Operations in a Multinational Industrial Corporation
}

\author{
Anna Sannö ${ }^{1,2}$, Maria T. Johansson ${ }^{3, *}$, , Patrik Thollander ${ }^{3}$, Johan Wollin 4 \\ and Birgitta Sjögren ${ }^{5}$ \\ 1 School of Innovation, Design and Engineering, Mälardalen University, SE-631 05 Eskilstuna, Sweden; \\ anna.sanno@oru.se \\ 2 School of Science and Technology, Örebro University, SE-701 82 Örebro, Sweden \\ 3 Division of Energy Systems, Linköping University, SE-581 83 Linköping, Sweden; patrik.thollander@liu.se \\ 4 Volvo Construction Equipment, SE-405 08 Gothenburg, Sweden; johan.wollin@volvo.com \\ 5 IVL, Swedish Environmental Institute; SE-411 33 Gothenburg, Sweden; \\ Birgitta.sjogren@consultant.volvo.com \\ * Correspondence: maria.johansson@liu.se
}

Received: 14 January 2019; Accepted: 29 January 2019; Published: 31 January 2019

\begin{abstract}
A large share of the energy efficiency improvement measures available for industrial companies remains unadopted due to the existence of various barriers to energy efficiency. One of the main means of overcoming barriers to energy efficiency is via energy management operations. The major parts of the published scientific papers have covered energy management on a company level or on a sector level. However, so far, the literature is scarce regarding empirical studies on energy management on a corporate level. With the aim of filling the research gap, the aim of this paper is to empirically assess the performance of an in-house energy management program adoption from the year of initiation and four years ahead in the multinational company Volvo CE. The paper was conducted as a case study including a participative approach, which has not previously been done in energy management research. This paper adds value, through complementing the existing literature on energy management on a factory or sector level, by highlighting the importance of leadership, speed of execution, and cultural transformation on a corporate level.
\end{abstract}

Keywords: energy efficiency; key elements; corporate energy management; energy management program; industry; case study; sustainable energy management; participative approach

\section{Introduction}

For the individual industrial company, it is of vital importance to remain cost-effective in all areas of the value chain in order to remain competitive. The more energy-intensive a company is, the more vital is the issue of improved energy efficiency. However, companies that are not as energy-intensive may have much larger energy improvement potentials left to deploy as energy efficiency historically has not been prioritized in non-energy-intensive companies [1,2]. In addition, non-energy intensive corporations, such as the automotive industry, have large potentials to save energy as they often consist of several production units worldwide. The Swedish Energy Agency defines a company as energy-intensive if it meets at least one of the following two requirements: 1) the cost of purchased and internally generated energy in the company amounts to at least three percent of the company's production value, and 2) the company's energy, carbon and sulphur taxes amount to at least 0.5 percent of the company's added value. Non-energy-intensive companies are, according to Rohdin et al. [3], defined as companies whose energy cost does not exceed two percent of sales. To manage energy improvement in a large corporation is a challenging task, for example, the locally 
distributed production units carry their own hidden costs of energy use. Another challenge is that the production units in a global network could have different cultures and management traditions in which the energy management program shall be integrated. To reach a sustained effort over time and deploy the potential energy-saving measures present, the global management has to efficiently integrate the energy management program and follow up energy improvements locally. Improved industrial energy efficiency remains a cornerstone in mitigating climate change, and therefore it is of importance to understand how to manage these programs for non-energy intensive companies as well.

Beginning with York et al. [4], a large number of scientific publications present results that show the existence of barriers in various sectors of the economy. Sorrell et al. [5] studied barriers to energy efficiency in the brewing and mechanical engineering industry. One of their key findings was that barriers differed between different sectors and regions. Schleich and Gruber [6] conducted econometric analyses for 19 sub-sectors in the German commercial and services sectors. Their results showed that the most important barriers were the investor/user dilemma and the lack of information about energy end-use patterns. Sorrell et al. [7] conducted a review of studies in barriers in the industrial sector. The review is based on an earlier contribution from Sorrell et al. [5], outlining six primary theoretical barriers to energy efficiency. The review of 160 publications in total shows that, among other things, the concept of hidden costs is one of the primary theoretical barriers [7]. Later contributions in the field include Johansson and Thollander [8], presenting a review of empirical research studies on barriers found in Swedish industry.

In order to achieve improvements, one of the most promising means of improving energy efficiency and reducing energy costs is by the implementation of an in-house energy management program. Beginning with Caffall [9], industrial energy management has been covered in a number of scientific studies. Schulze et al. [10] and May et al. [11] present comprehensive reviews in the field of industrial energy management. However, there is a scarcity of findings in the literature on how to characterize successful energy management program adoption. With the exception of [12-14], which evaluated successful energy management program adoption in different Swedish industrial sectors, there are few empirical studies that apply a framework to evaluate the performance of industrial energy management. Moreover, the major parts of the published scientific papers have covered energy management on a company level or on a sector level. So far, the literature lacks empirical studies on energy management related to the different organizational levels in multinational industrial corporations.

With the aim of filling the research gap, the aim of this paper is to empirically assess the performance of in-house energy management program adoption in the multinational company Volvo Construction Equipment (Volvo CE), as a part of the Volvo Group corporation. The study is also new in the sense that the process of adoption is monitored during a four-year period. The paper applies the developed framework of ten key elements (success factors) for effective in-house energy management presented by Johansson and Thollander [8]. To the authors' awareness, this paper represents a novel attempt to explore the issue of in-house energy management program adoption on different organizational levels in multinational corporations. The study was conducted based on three perspectives: 1) the strategic program on the global management level at Volvo CE; 2) the role of corporate managers and experts (Volvo Group level); and 3) the factory level (plant level down to unit level).

The paper starts with a description of the theoretical framework [8] on key elements important to consider in adopting an energy management program, followed by a description of the method and the case studied. In the following section, the analysis, combining theoretical and empirical findings, is presented. In the concluding sections the results and implications are discussed. The concept of hidden costs includes overhead costs related to the investment as well as the cost of collecting and analyzing information and the cost of production disruptions. The other five theoretical barriers that [7] outlines are imperfect information, risk, access to capital, split incentives, and bounded rationality. 


\section{Theory}

Research on energy management in industry is an emerging field of research, one of the first empirical studies on the issue being Caffall [9]. For practitioners, the work of Turner [15] remains one of the most widely-used books in the area of energy management. In later years, thanks to the international energy management system standard, ISO 50001, an increasing number of papers have been published and the area is experiencing a rise in research activity. Below, scientific publications are presented, and structured in accordance with the framework presented by Johansson and Thollander [8].

\subsection{Top-Management Support}

Bowonder [16] found that the commitment of senior management is of great importance in relation to successful energy management execution. Johansson and Thollander [8], in an empirical study of energy management, outlined the need for top management support in order to successfully carry out an in-house energy management program. Suk et al. [17], in a study of energy management in Korea, found that among other factors support from top management is a critical factor, in order for the implementation of energy efficiency measures to take place.

\subsection{Long-Term Energy Strategy with Goal Formulation}

Lambert [18] were the first to outline the need for a long-term energy strategy in successful energy management operations. In later empirical studies, Thollander et al. [19] found this factor to be one of the highest ranked in the Swedish pulp and paper industry. Ates et al. [20] confirms the importance of this in their study of energy management in the Turkish industry sector. In a review of Swedish studies on driving forces by Johansson and Thollander [8], including the previously outlined study [19], the existence of a long-term energy strategy was found to be one of the highest ranked drivers for energy efficiency improvements in the pulp and paper, steel, foundry, non-energy-intensive manufacturing, and industrial SME (small and medium-sized enterprise) sectors. In the formulation of the strategy, goals are preferably set [21].

\subsection{Energy Planning}

As first outlined by Lambert and Stock [18], energy planning remains a cornerstone in successful energy management operations. Preferably, as outlined by Caffall [9], a company formulates a short-term plan, covering a one-year period, and a longer plan, covering multi-year periods. Rudberg et al. [22] further outlines the need for energy planning, but as stated by Turner [15], planning is one of the most important parts of the energy management program, and for most technical people it is the least desirable.

\subsection{Energy Manager Position}

A person dedicated to working solely with energy management could, as stated by Sorrell et al. [5], not always be motivated as the potential cost reductions achieved cannot cover the staff costs for energy management. In such cases, the commitment of an energy manager may not need to be $100 \%$, but nevertheless clear dedication of responsibility is of great importance. Gordić et al. [23], in their study of a Serbian car manufacturer, found that the most crucial part of in-house energy management is an energy manager.

\subsection{Submetering}

In order to overcome the split incentive barrier, energy costs need to be allocated based on submetering, preferably at division level and not per square meter or per number of employees for specific departments and divisions within a company. Without correct allocation of energy costs, 
the division or department manager will be reluctant to place their own budget funding in investments in improved energy efficiency measures [12].

\subsection{Formulation of KPIs}

The formulation of KPIs (Key Performance Indicators) is of crucial importance in order to be able to follow up and evaluate performance of the management program [21]. Key performance indicators and indexation beyond the supply of energy related to production output remain rare.

\subsection{Energy Controllers at Floor-Level Position}

The company energy manager may be greatly supported by having a division energy controller at each shift among the shop-floor personnel. This person, apart from supporting the energy manager with administrative activities, may directly inform the energy manager about production shutdowns, enabling the energy manager to reduce to a minimum all non-critical processes such as ventilation and compressed air. Based on findings from a case study of 11 steel mills, Johansson [24] recommends each mill to have an energy host, i.e., a person in each shift being responsible for the energy issue.

\subsection{Education, Vizualisation, and Energy Competition}

Education is outlined by Caffall [9] as an important means for improving the overall performance of an in-house energy management program and underscores that this may take place in steps beginning with the persons in the company being directly responsible or having authority over the energy issues. References $[15,24,25]$ outline the need for visualization. Bunse et al. [26] further states that software suitable for visualization of KPIs remains rare. Energy competition, in order to provide rewards, may also be practices in order to motivate staff [27].

\section{Method}

The study was conducted as a case study inspired by Yin [28]. As a descriptive framework, the paper applies the framework of key elements, or success factors, for in-house energy management program adoption developed by Johansson and Thollander [8]. The case company is the Volvo Group, an automotive manufacturing corporation with several business units and around 100,000 employees worldwide. The particular focus in the study is on Volvo CE, as a business unit, producing construction machines in thirteen plants worldwide. The main manufacturing operations in the plants are machining, painting, welding, and assembly.

The case study was conducted based on three perspectives: 1) the strategic program on the global management level at Volvo CE, 2) the role of corporate manager and experts (Volvo Group level); and 3) the factory level (plant level down to unit level). It also describes the implementation and operationalization of an energy efficiency program from 2013 and four years ahead. The data were collected during 2013-2016 in a close collaboration setting between academia and industry. One enabler for the collaboration was that an academic partnership was established between the company and university, in a so-called co-producing setting [29] as a requirement for governmental funding of the research. This provided the first author with access to the discussions and dialogue before the energy program was initiated. The other enabler is that the first author had no formal role in the program and was introduced and supported by the management as an employee researching sustainability for five years. This provided a freedom in the formulation of the research questions and corresponding research methods but also full access to the organization and the program.

To achieve the aim of the study, to empirically assess the performance of the in-house energy management program adoption, one has to realize that the adoption needs to be followed over time. The research should rather follow the path of the adoption as it is managed by the organization, rather than as a researcher deciding to follow single events. Therefore, the research approach in the case study was influenced by participatory and longitudinal research [30], see Table 1 for data collection. A case study was an appropriate method since the phenomenon was studied in its natural 
setting, to increase the understanding of why things happened, what happened, and how the program was proceeding over time to identify the variables that made the energy program successful or not [31]. The influence from a longitudinal research approach enabled the researchers to gain rich insights by observing the evolution of the energy management over time. A longitudinal approach is suitable for iterative investigations of complex and dynamic processes as it allows the researcher to collect new data, revisit the site of previous data collection, and develop the methods used in data analysis [30]. Results from observations were triangulated with company documents and reflections from meetings. The reflections were done while taking notes from the meetings and included the progress, factors discussed and the team members' concerns. The researcher could, by observation in different network meetings on the three organizational levels, in workshops, and by documents, study the initiative and its initiation.

Table 1. Information about the data collection process during the period 2013-2016.

\begin{tabular}{|c|c|c|c|}
\hline Respondents & $\begin{array}{c}\text { Context of Data } \\
\text { Acquisition Occasions }\end{array}$ & $\begin{array}{c}\text { Number of } \\
\text { Occasions (Duration) }\end{array}$ & Methods \\
\hline Energy, environmental specialists & $\begin{array}{l}\text { Global Volvo Group } \\
\text { network meetings }\end{array}$ & 7 (2-4 hours) & $\begin{array}{l}\text { Observations, } \\
\text { notes, documents }\end{array}$ \\
\hline $\begin{array}{l}\text { Environmental director, former } \\
\text { corporate expert in energy }\end{array}$ & Global corporate experts & 2 (1 hour) & Interviews \\
\hline $\begin{array}{l}\text { Global and regional leaders of } \\
\text { health safety environment }\end{array}$ & $\begin{array}{l}\text { Global and Regional } \\
\text { Volvo CE Network } \\
\text { meetings, face-to-face } \\
\text { workshops, online } \\
\text { meetings }\end{array}$ & 27 (1-8 hours) & $\begin{array}{l}\text { Observations, } \\
\text { notes, documents }\end{array}$ \\
\hline $\begin{array}{l}\text { Project team members/corporate } \\
\text { experts, energy managers }\end{array}$ & $\begin{array}{l}\text { Plant meetings and site } \\
\text { visits: one plant in Brazil, } \\
4 \text { plants in Sweden }\end{array}$ & 15 (4-8 hours) & $\begin{array}{l}\text { Observations, } \\
\text { notes, documents }\end{array}$ \\
\hline $\begin{array}{l}\text { Project team members from } \\
\text { different departments in the plant }\end{array}$ & $\begin{array}{l}\text { Hallsberg, plant } \\
\text { 2013-2016 }\end{array}$ & 23 (1 hour) & $\begin{array}{c}\text { Observations, } \\
\text { notes, documents }\end{array}$ \\
\hline
\end{tabular}

In addition, an interview was held with one of the corporate experts, who left the position in November 2013, to reflect on before and after initiation of the program. Later on, after the launch of the program and several plant visits and start-ups, one of the plants was selected to be studied more in detail. The reason for selection of this plant was the previous lack of activities within the energy management area, the lack of resources in the initial stage but also the motivation shown by the staff to work in the program. Observations were made in the energy meetings held every second week by taking notes of the participants' attendance and meeting behavior, their assigned activities, accomplished tasks, and also the achieved results. Additionally, the progress of the other plants was followed on a higher level by observations at network meetings and presentations held by energy managers.

The developed framework presented by Johansson and Thollander [8] was selected as being a framework for the analysis, since it presents a holistic view of energy management. The data analysis was done in two parts. The first part was coding the material into the framework. The second part was to identify the constituents of a sustainable approach to manage an in-house energy management program. The data analysis was influenced by an interventionist approach [32]. This means that a reflective dialogue was initiated during the end of the data collection and the analysis. The managers of the corporate program were involved in this research process, to the extent that they are also co-authoring this paper. This was seen as an appropriate method to enhance the knowledge transfer and researching with practice $[29,33]$. This means that the researcher is being reflective together with practitioners and having real-time impact, rather than as a traditional researcher, researching on the companies and rather reporting the results to academia [34]. 
A workshop was conducted with the industrial researcher (first author), the headquarter-based global energy manager and the corporate energy expert. The three persons provided perspectives from three levels in the company.

\section{Implementation and Operationalization of an Energy Efficiency Program at the Volvo Group}

The Volvo Group corporate journey on improved energy efficiency as an environmental concern started in the 1990s. An energy team started to consolidate expertise from each of the Swedish plants. By 2004, the corporate headquarters employed an energy manager in order to develop the strategic path for future needs. An internal ambition to improve energy efficiency by $50 \%$ per produced unit was established. An energy action plan was created related to different themes such as ventilation, lighting, etc. The agenda was extended by sharing energy performance measures and best practices. The minimum requirement at that time was to perform internal energy audits but it did not include measures and did not seem to drive change. Some impact on the organization happened during the large economic decline in 2008 and 2009. The uncertainty due to the recession hindered the plants from making investments; on the other hand, resources were available to work on the energy-saving activities. Some of the plants started to achieve good results in the energy efficiency programs. At the Vara plant, major energy efficiency improvements were made by continuous improvement work. The driver was considered to be related to key persons who initiated and managed the energy-reducing activities. The culture, by having a core value of environmental concern rooted in the organization, enhanced change. At this point, the corporate company established a collaboration with the non-governmental organization World Wild Fund for Nature (WWF) to become a Climate Saver, being the only automotive company in the program [35].

Within the business unit of Volvo CE, a new global director was appointed in 2013, who had the ambition to include energy in the industrial strategies and the implementation of these. This was a new start of the energy management program. At a workshop in March 2013, a new approach was launched amongst the global and regional directors. So far, the plants of Volvo CE had fulfilled the requirements to do internal energy audits, and a dashboard measurement had been introduced, but still activities on a structural basis did not result in tangible figures of energy efficiency improvements. An important decision was taken at the meeting: it was decided to start with energy conservation, idle electricity, rather than trying to get investments for energy efficiency or renewable energy. This was based on the share of best practices from Vara, to work with continuous improvement and having employees acting as "change agents" locally. Based on lean thinking and waste elimination, the foundation of the strategy and planning was created for the forthcoming years. A prioritization made on what plants to focus on was visualized in a common global A3 and using the Pareto diagram, see Figure 1. This was later used for communication to the global organization on all levels.

A strategic action plan was developed based on the current state, needs, and gaps. After the workshop, the strategic documents were completed with figures and the order of prioritization was communicated to the organization in less than one month's time. The environmental KPIs were re-defined and sent out in a review process. The justification that energy is something that we need for operation but also continuously costs us money was communicated in the culture and the organization. The focus was set on cost to be the driver for change: "We make savings but we are also doing good things for the environment".

At the next face-to-face energy meeting in September 2013, it was approved by the group of energy managers to use the standard kaizen to map the energy end-use at different levels, and a policy was set up to turn off energy when production was off. Local plant visits were then performed by the established networks, enhanced by active communication and increased credibility that the energy program was important. The process was, however, slowed down by organizational issues; several of the people appointed to implement the program locally at the plants changed their positions. It also took longer time and more effort to get the governance structure in place (at some plants more than one year), involving the top management and to find resources locally. During this phase 
the energy efficiency improvements were just starting to show results. Even if the monitoring was available on the plant level there was no clarity in what could be done to improve energy efficiency. The efficiency improvements could not be traced if it was a warm summer or just lower production that week, which proved that the old KPI was not driving any change. Later on, it showed that the decision to have corporate experts appointed to report and visualize the data of the idle electricity was fundamental. Energy walks were arranged systematically. Weekly and monthly meetings established the governance structure. It had the mind-set of continuously improving the way of working on all levels. One example of a less successful activity was the creation of a competition between the plants in the Earth Hour program. This created a cultural barrier between the plants rather than enhancing their collaboration.

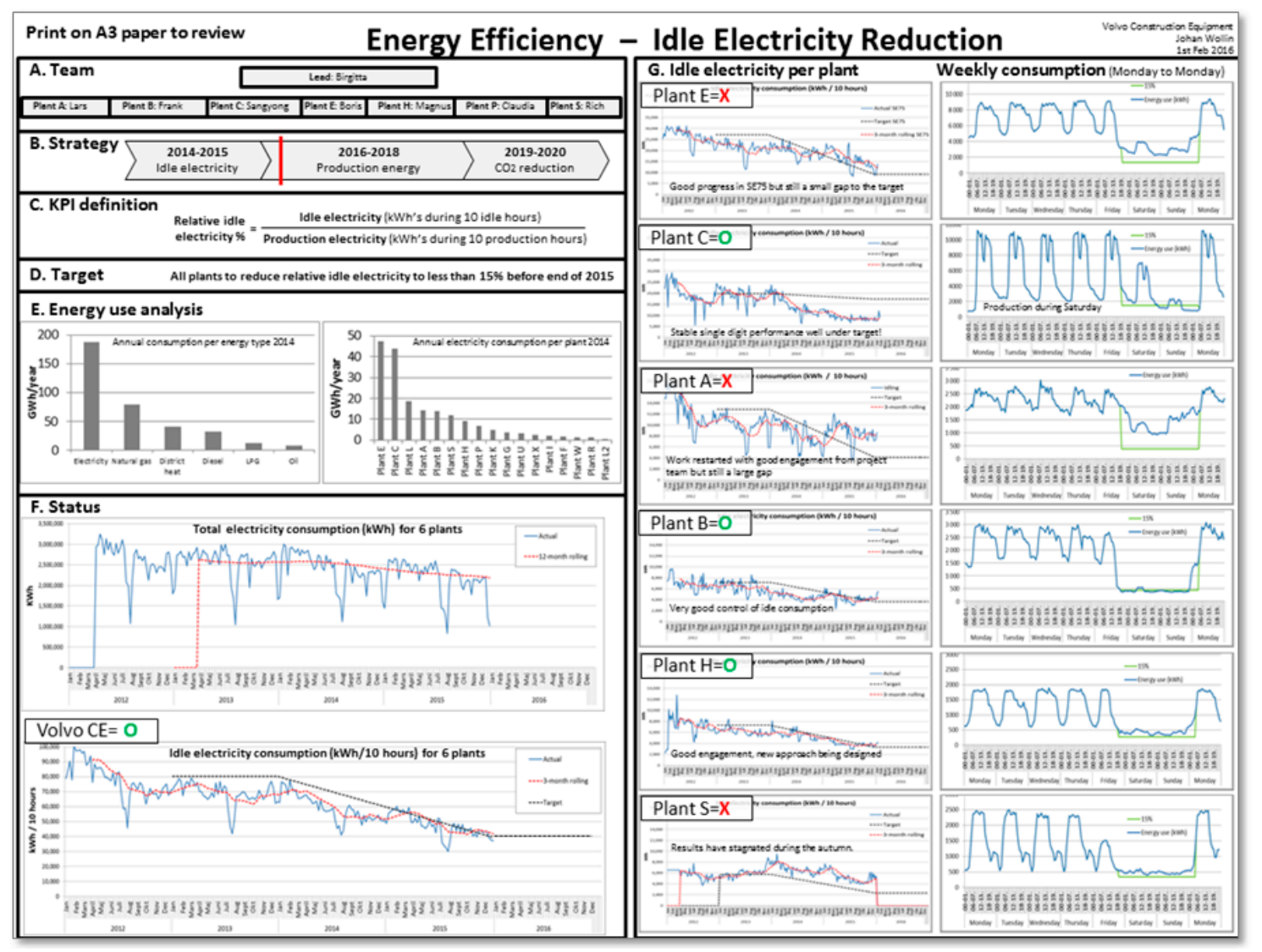

Figure 1. An example of the A3 used to enhance communication in the energy program. The A3 shows the current state of energy use, the progress of the program, and the desired state for all the plants.

One of the plants that had a slow start up was the Hallsberg plant. It is a small plant in the group, employing approximately 500 people, but still regarded as one of the major users of energy. The plant has three major operations: weld, paint, and assembly, where the paint shop accounts for approximately $50 \%$ of the electricity used. The amount of total electricity used in the plant was 9760 MWh by 2013 and by the end of 2016 the total amount of electricity was reduced to $7871 \mathrm{MWh}$. The environmental coordinator position was vacant during the roll-out of the program in 2013 and the energy manager became a team leader for one of the workstations by the end of that year. This person was appointed for two hours a week by the local organization to fulfill the expected requirements from the global energy team. In order to fulfill the expected actions, the person became dependent on the contribution of persons from the daily operations. An energy group was formed with maintenance, engineering, estate, and operators, and later the new environmental coordinator became an important player for the long-term targets and local management communication. During the period 2014-2016, the number of people attending the meeting every second week was constantly seven to nine people. 
The reason for this high attendance is related to the meeting as being open-minded; every proposal for efficiency improvements was considered and if manageable, taken into action. The focus was set to work on the idle electricity. After six months, the structure of reporting data and finding actions concerning what, who, and when had been established. The attention from the global energy team was often mentioned at the meetings; the direct information and the requests for results pushed the group forward. By November 2014, a list of improvements and a list of investments had been developed, including a measurement system on the unit level. By 2016, with the number of 230 closed action items on the list, the plant had already reached the level of improvement required by the targets set for 2020 . The items worked on had been all from behavioral change of the staff to becoming more aware of the energy and acting upon a daily basis, to reduce temperatures, detect leakages and by changing equipment both in the processes and in the facilities. The targets were therefore stretched by the global energy team in 2016 and introductory meetings about how to reach ISO 50001 certification were held. During this time, top management and engagement have varied; four different plant managers have been in the position since the start of 2013, and major redundancies for the staff were announced in 2016. Nevertheless, the approach has sustained and has delivered the expected results. The total final saving at the end of 2016 was more than $30 \%$ of idle energy electricity compared with 2013, resulting in a saving of $2.5 \mathrm{GWh}$ for the single plant and the long-term targets from WWF were already met. For the whole corporation, the savings resulted in reduced idle energy use to up to $30 \mathrm{GWh}$ in 2016 compared with 2013, showing the hidden cost and the potential of expanding the activities of energy saving in the company. Figure 2 shows the total cumulative energy savings between 2014 and 2018.

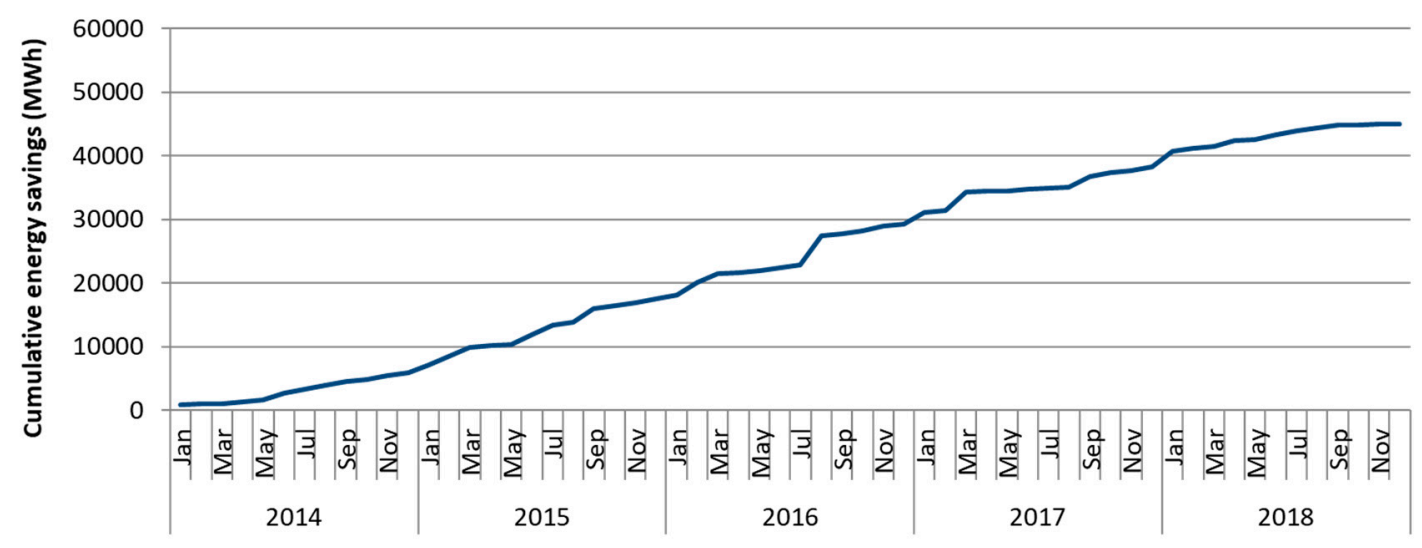

Figure 2. Total cumulative energy savings at Volvo Construction Equipment (Volvo CE) because of implemented energy efficiency measures during the period 2014-2018.

\section{Analysis of the Process of Adopting an Energy Management Program}

Several factors were shown to be important for a sustainable governance structure. Table 2 shows the performance of key factors for efficient energy management before and after the specific program was started. Tangible results from the program showed how energy savings led to major cost reductions.

Analyzing the development of the energy management program on the corporate level, important elements on the business unit level and plant level have been identified that enable the program to be fully implemented. The most fundamental factor pointed out at the workshops was the appointment of an energy manager. A skilled energy manager was required at all the organizational levels. First of all, the global manager was skilled in lean manufacturing, able to prioritize and able to find ways to execute quickly, which resulted in a focused and energized management. Secondly, by speaking the local languages and visiting the plants several times a year his credibility and the engagement from the local sites increased. The corporate expert supported him by having a more active role than before, showing himself locally supporting both technical and management issues. These persons had the benefit of being appointed long-term; change in this role would delay the program. At the plant 
level, a dedicated energy kaizen facilitator had a clear responsibility to execute the idle energy project (even though it was only a few hours a week). The local energy managers at the sites were appointed to be able to manage long-term projects applying a structured way of working.

Table 2. The performance of key elements for efficient energy management at Volvo CE's three organizational levels, before and after 2013, leading to energy efficiency improvements and cultural transformation.

\begin{tabular}{|c|c|c|}
\hline Organizational Level & Before 2013 & After 2013 \\
\hline \multicolumn{3}{|c|}{ Importance of long-term energy strategy with goal formulation } \\
\hline Global management & $\begin{array}{l}\text { Multiple focuses on } \mathrm{CO}_{2} \text { reducing } \\
\text { emissions. Target on efficiency } \\
\text { improvements } 50 \% \text {, but not } \\
\text { driving change. Requesting } \\
\text { energy audit. }\end{array}$ & $\begin{array}{l}\text { Vision 2013-2017, planned roll-out, focusing } \\
\text { on idle electricity and waste elimination. } \\
\text { Prioritization of plants, governance structure } \\
\text { with a frequent, short-term follow-up. New } \\
\text { initiative integrated-keeping existing } \\
\text { governance and procedures. }\end{array}$ \\
\hline Corporate expert & $\begin{array}{l}\text { Available on demand, but often } \\
\text { this person was not even known at } \\
\text { plant level. }\end{array}$ & $\begin{array}{l}\text { Continuous support and coaching, Structured } \\
\text { follow-up of results planned on both local } \\
\text { and global levels. }\end{array}$ \\
\hline Plant level & $\begin{array}{l}\text { Investment need and the unit did } \\
\text { not talk to management, i.e., lower } \\
\text { prioritization, motivated } \\
\text { individuals driving change. New } \\
\text { initiatives came as an add-on. }\end{array}$ & $\begin{array}{l}\text { Plants prioritized based on energy end-use, } \\
\text { focus on saving money. Integration of new } \\
\text { strategic initiative creating long-term } \\
\text { continuity in the organization. }\end{array}$ \\
\hline \multicolumn{3}{|c|}{ Importance of energy planning and systematic approach } \\
\hline Global management & $\begin{array}{l}\text { Supporting on demand. Some } \\
\text { plants have performed energy } \\
\text { audits. }\end{array}$ & $\begin{array}{l}\text { Meeting structure including all levels, speed } \\
\text { of implementation and risk reduction } \\
\text { managed by prioritizing small improvements. } \\
\text { Training provided. }\end{array}$ \\
\hline Corporate expert & $\begin{array}{l}\text { Supporting on demand, but often } \\
\text { this person was not known at } \\
\text { plant level. }\end{array}$ & $\begin{array}{l}\text { Active role in the governance structure, } \\
\text { developing procedures with continuous } \\
\text { improvement. Creating transparency } \\
\text { between the plants. }\end{array}$ \\
\hline Plant level & $\begin{array}{l}\text { Cultural local drives to identify } \\
\text { the potentials in the energy audit, } \\
\text { improvements on the shop floor } \\
\text { not consolidated. Investments, } \\
\text { single equipment focus. }\end{array}$ & $\begin{array}{l}\text { Systematic approach, realistic activities with } \\
\text { end dates. External audits, internal audits } \\
\text { such as night walks enhancing the continuous } \\
\text { improvement, seeking for new approaches } \\
\text { and new knowledge on plant level. }\end{array}$ \\
\hline \multicolumn{3}{|c|}{ Importance of metering and control } \\
\hline Global management & $\begin{array}{l}\text { One overall key measurement, } \\
\text { target did not drive change. }\end{array}$ & $\begin{array}{l}\text { New key measurement idle electricity rather } \\
\text { than based on production rate. Frequent } \\
\text { follow-up, presented on management level } \\
\text { and adjustments on plant level. }\end{array}$ \\
\hline Corporate expert & Follow-up. & $\begin{array}{l}\text { Expertise for finding relevant definitions, } \\
\text { providing the overall metering and results } \\
\text { sharing, the targets' breakdown. }\end{array}$ \\
\hline Plant level & $\begin{array}{l}\text { Follow-up monthly on plant level } \\
\text { but large variations depending on } \\
\text { weather conditions, production } \\
\text { rate etc. }\end{array}$ & $\begin{array}{l}\text { Frequent follow-up-correct allocation of the } \\
\text { energy savings. Measurement system } \\
\text { adapted to enhance continuous improvement } \\
\text { and by this knowledge creation. }\end{array}$ \\
\hline
\end{tabular}

The aspect of establishing full top-management support of the in-house energy management activities could be seen in the global manager's work to anchor the program at all levels. It was noted that the awareness of how to communicate, visualize results, and be physically present locally was important to get the attention of the plant management team. 
The long-term commitment that was established by a vision in 2013-2017 had a planned roll-out for each site, and prioritized focusing on idle electricity and waste elimination. Attention was placed to develop a reliable KPI, which enabled follow-ups and was not as dependent on the production rate or outdoor weather conditions. There was also a prioritization of plants, i.e., which plants to focus on within the company group, and a governance structure was set up with a frequent, short-term follow-up. The long-term planning also covered new initiatives to be integrated while keeping the existing governance and procedures. This was seen when the WWF contract was re-signed. The governance and structure enhanced communication, and just a week after the contract it was renewed from headquarters, and the plants were made aware of the new directives.

Further, the local plants were continuously supported and coached by the corporate experts to push the long-term strategic initiatives in the organization. As the plants were prioritized based on their energy end-use and visualized in the A3 (see Figure 1), metering on the plant level led to awareness about the achievements throughout the organization. Internal and global communication of the project by the global manager established a sharing of results. The corporate expert followed up the plants every second week and the local energy manager reported and visualized energy performance in the $\mathrm{A} 3$.

This created a comparison and awareness between the plants, which raised questions about best practice. However, highlighting competition in energy efficiency improvements was shown to be unsuccessful; while setting up a competition for a winner of the Earth Hour, the plants started to compete, which created a culture that, when reviewed, was considered to be negative for knowledge-sharing. Rather, the reporting of results created a feeling of inclusiveness of belonging to the global program.

The approach was developed over time by continuous improvement, not only the energy efficiency improvement activities but also the ways to approach the local organization. Initiatives that were found successful at one plant were shared. Arranging night walks, teaching the staff and inviting energy managers from the other plants increased the awareness of activities that could lead to energy efficiency improvements. The sub-metering was done on different levels; while some plants decided to invest in measurement systems quite early, others first took time to understand how energy could be saved using the knowledge they learnt from efficiency improvements in the overall plant measurement. The metering was used for continuous improvement, which enhanced knowledge creation.

\section{Discussion}

This case study showed the importance of global and local interaction when adopting an energy management program in a corporate group. To deploy the full energy efficiency potential in a corporate group, the elements for success regarding in-house energy management program adoption have to be considered at all organizational levels of the company, as seen in the before and after scenarios. Leadership in this chain is of key importance; if one organizational link is weak, the in-house energy management program seemed to lose pace in the change initiative, as also shown by including time aspects when studying organizational change [36]. This adds a temporal dimension to the program; having a fast speed of execution in an environment with multiple initiatives also influences cultural transformation regarding energy efficiency improvements. A synthesis of the results is presented in Figure 3. The first step was to consider the role of energy managers at several levels. Secondly, an integrative long-term commitment was found to be of importance involving a systematic approach with visualization and education initiatives, built on continuous improvement to develop both working methods and energy efficiency improvement activities. The procedures allowed each kaizen facilitator to adapt to the local plant. Credibility was found to be one of the most important factors to maintain the program's long-term effort. Further, relevant KPIs and targets are of importance, since these are regarded as essential for having active communication and creating long-term attention from the top and plant management. 


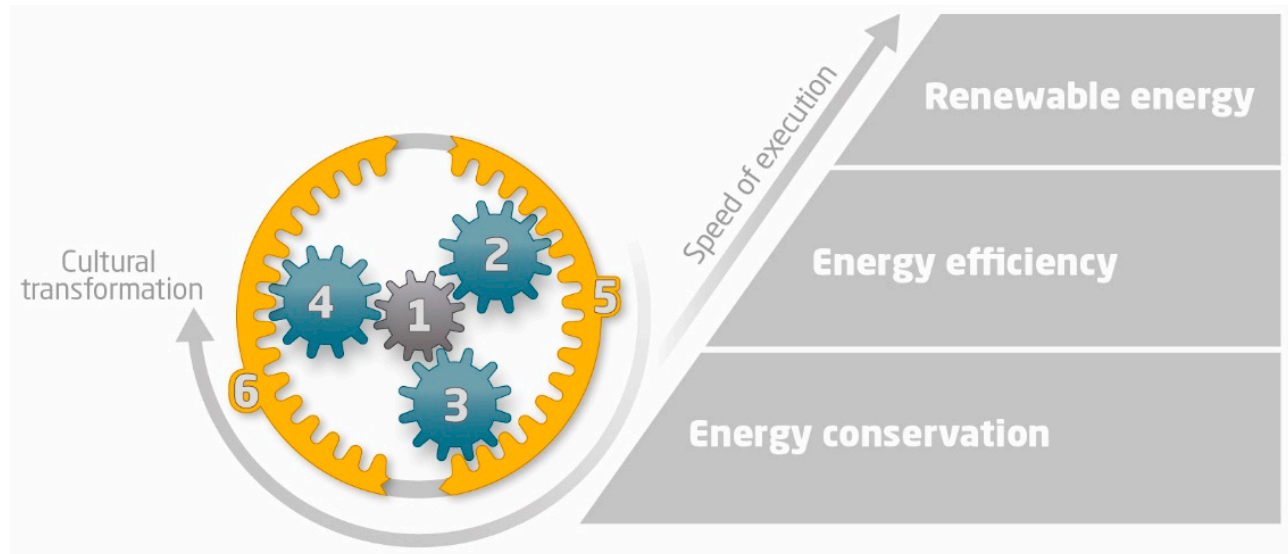

Figure 3. A symbolic model showing how energy management has been built up at Volvo CE. The elements are ranked by degree of importance. Central to the organization is to (1) appoint energy managers having both the skills and networks relevant to the position, (2) establish long-term commitment, vision, and follow-up, (3) utilize a systematic approach, (4) develop continuous improvement, (5) establish multiple sources of credibility, and (6) develop relevant KPIs and targets. This enhances cultural transformation and is kept in motion by active management at all levels in the corporation with a speed of execution.

To manage energy improvement in a large corporation is a challenging task, as the locally distributed production units carry their own hidden costs of energy use. In this paper, it shows how the company managed to visualize the hidden cost of single energy efficiency measurement levels. However, as concluded by the global energy director in the last workshop, there is also potential to create engagement internally if one also considers non-energy benefits related to increased productivity [37], which is seen as an area to include in further studies.

\section{Conclusions}

This paper presents a view of how a non-energy intensive manufacturing company has managed an energy management program on a corporate level. A corporate level increases the complexity of adopting an energy management program, as the program has to work in plants with different cultures and local management. The paper describes the importance of organization and culture in order to achieve a sustainable long-term approach for environmental and economic results within an energy management program. The energy management program adopted was inspired with lean manufacturing principles, which showed an enhanced need of active leadership in order to attain speed of execution. This paper adds value through supplementing the existing literature on energy management on a factory or sector level by highlighting the importance of leadership, speed of execution and cultural transformation on a corporate level. For corporations, the paper points out how the single elements are important for the whole program's success. By carefully managing the elements, the program was successfully implemented despite different cultures in the plant around the globe. Corporations should focus on implementing each element, but also assure that there is an interaction between top-down and bottom-up management. Using lean management tools, such as the $\mathrm{A} 3$, is recommended for the case of showing the program progression and to communicate the same message in the organization and to the WWF.

Results show that the introduction of an energy management program at Volvo CE led to more efficient energy management. The key elements that characterize efficient energy management were found in the corporate group after the introduction of the program. This paper presents them from a holistic perspective, showing how different key elements interact $[8,10]$ rather than focusing on single key elements.

Our main methodological conclusion is that a case study using a participative approach could enhance our understanding of energy management and supplement previous research applying 
case studies using interviews or questionnaires as the main means of data collection. For example, Pagell [34] claims that the research tradition in the management field is mostly retrospective, and that participatory research can bring benefit from having relevant and direct practical impact rather than reporting about what practice has already been done.

The descriptive framework adopted in the study enhanced the generalizability of the study and also provided guidance to other corporate energy managers on how to execute an energy management program. Furthermore, it provides a framework for researchers on how to evaluate, analyze, and suggest improvements about an energy management program at several levels, using a systems perspective.

Author Contributions: Conceptualization, A.S., M.T.J. and P.T.; Methodology, A.S.; Validation and Formal Analysis, A.S., J.W. and B.S.; Investigation, A.S.; Resources, J.W. and B.S.; Writing-First Original Draft Preparation, A.S.; Writing-Second Original Draft Preparation, M.T.J., A.S. and P.T.; Writing-Review \& Editing, M.T.J., P.T. and A.S.; Visualization, A.S.; Supervision, P.T.; Project Administration, J.W. and B.S.

Funding: This research work was funded by the Knowledge Foundation (Stiftelsen för Kunskaps-och Kompetensutveckling) within the framework of the INNOFACTURE Research School and the participating companies, and Mälardalen University.

Acknowledgments: The participants in the energy efficiency program contributing to the study at Volvo Group and Volvo CE are thanked for their openness and sharing of information. The supervision team Mats Deleryd and Anders Fundin at Mälardalen University and Niklas Nillroth, Volvo CE are also gratefully acknowledged.

Conflicts of Interest: The authors declare no conflict of interest. The funders had no role in the design of the study, in the collection, analyses, or interpretation of data, in the writing of the manuscript, or in the decision to publish the results.

\section{References}

1. Ramirez, C.A.; Patel, M.; Blok, K. The non-energy intensive manufacturing sector. An energy analysis relating to The Netherlands. Energy 2005, 30, 749-767. [CrossRef]

2. Backlund, S.; Broberg, S.; Ottosson, M.; Thollander, P. Energy efficiency potentials and energy management practices in Swedish firms. In Proceedings of the ECEEE Industry Summer Study, European Council for an Energy Efficient Economy, Arnhem, The Netherlands, 11-14 September 2012.

3. Rohdin, P.; Thollander, P. Barriers to and driving forces for energy efficiency in the non-energy intensive manufacturing industry in Sweden. Energy 2006, 31, 1500-1508. [CrossRef]

4. York, C.M.; Blumstein, C.; Krieg, B.; Schipper, L. Bibliography in Institutional Barriers to Energy Conservation; Lawrence Berkeley Laboratory and University of California: Berkeley, CA, USA, 1978.

5. Sorrell, S.; O'Malley, E.; Schleich, J.; Scott, S. The Economics of Energy Efficiency: Barriers to Cost-Effective Investment; University of Sussex: Brighton, UK, 2004.

6. Schleich, J.; Gruber, E. Beyond case studies: Barriers to energy efficiency in commerce and the services sector. Energy Econ. 2008, 30, 449-464. [CrossRef]

7. Sorrell, S.; Mallett, A.; Nye, S. Barriers to industrial energy efficiency: A literature review; United Nations Industrial Development Organization: Vienna, Austria, 2011.

8. Johansson, M.; Thollander, P. A review of barriers to and driving forces for improved energy efficiency in Swedish industry-Recommendations for successful in-house energy management. Renew. Sustain. Energy Rev. 2018, 82, 618-628. [CrossRef]

9. Caffall, C. Learning from Experiences with Energy Management in Industry; Centre for the Analysis and Dissemination of Demonstrated Energy Technologies (CADDET): Sittard, The Netherlands, 1995.

10. Schulze, M.; Nehler, H.; Ottosson, M.; Thollander, P. Energy management in industry-A systematic review of previous findings and an integrative conceptual framework. J. Clean. Prod. 2016, 112, 3692-3708. [CrossRef]

11. May, G.; Stahl, B.; Taisch, M.; Kiritsis, D. Energy management in manufacturing: From literature review to a conceptual framework. J. Clean. Prod. 2017, 167, 1464-1489. [CrossRef]

12. Thollander, P.; Ottosson, M. Energy management practices in Swedish energy-intensive industries. J. Clean. Prod. 2010, 18, 1125-1133. [CrossRef] 
13. Brunke, J.C.; Johansson, M.; Thollander, P. Empirical investigation of barriers and drivers to the adoption of energy conservation measures, energy management practices and energy services in the Swedish iron and steel industry. J. Clean. Prod. 2014, 84, 509-525. [CrossRef]

14. Sa, A.; Thollander, P.; Cagno, E. Assessing the driving factors for energy management program adoption. Renew. Sustain. Energy Rev. 2017, 74, 538-547. [CrossRef]

15. Turner, W.C. Energy Management Handbook, 7th ed.; Fairmont Press Inc.: Lilburn, GA, USA, 2009.

16. Bowonder, B. Energy management awareness programme for senior executives. Environmentalist 1984, 4, 125-129. [CrossRef]

17. Suk, S.; Liu, X.; Sudo, K. A survey study of energy saving activities of industrial companies in the Republic of Korea. J. Clean. Prod. 2013, 41, 301-311. [CrossRef]

18. Lambert, D.M.; Stock, J.R. The corporate energy policy: A management planning perspective. Long Range Plan. 1979, 12, 45-51. [CrossRef]

19. Thollander, P.; Ottosson, M. An energy efficient Swedish pulp and paper industry-Exploring barriers to and driving forces for cost-effective energy efficiency investments. Energy Effic. 2008, 1, 21-34. [CrossRef]

20. Ates, S.A.; Durakbasa, N.M. Evaluation of corporate energy management practices of energy intensive industries in Turkey. Energy 2012, 45, 81-91. [CrossRef]

21. Rietbergen, M.G.; Blok, K. Setting SMART targets for industrial energy use and industrial energy efficiency. Energy Policy 2010, 38, 4339-4354. [CrossRef]

22. Rudberg, M.; Waldemarsson, M.; Lidestam, H. Strategic perspectives on energy management: A case study in the process industry. Appl. Energy 2013, 104, 487-496. [CrossRef]

23. Gordić, D.; Babić, M.; Jovičić, N.; Šušteršič, V.; Končalović, D.; Jelić, D. Development of energy management system-Case study of Serbian car manufacturer. Energy Convers. Manage. 2010, 51, 2783-2790. [CrossRef]

24. Johansson, M.T. Improved energy efficiency within the Swedish steel industry-the importance of energy management and networking. Energy Effic. 2015, 8, 713-744. [CrossRef]

25. Christoffersen, L.B.; Larsen, A.; Togeby, M. Empirical analysis of energy management in Danish industry. J. Clean. Prod. 2006, 14, 516-526. [CrossRef]

26. Bunse, K.; Vodicka, M.; Schönsleben, P.; Brülhart, M.; Ernst, F.O. Integrating energy efficiency performance in production management-Gap analysis between industrial needs and scientific literature. J. Clean. Prod. 2011, 19, 667-679. [CrossRef]

27. Stawicki, B.; Lozo, B.; Lajić, B. Energy management guidelines in pulp and paper production. Cellul. Chem. Technol. 2010, 44, 521-529.

28. Yin, R. Case Study Research: Design and Methods, 5th ed.; SAGE Publications, Inc.: London, UK, 2014.

29. Knowledge Foundation. "Co-production" The Knowledge Foundation's concept of co-production. Available online: http:/ / www.kks.se/om-oss/in-english/co-production/ (accessed on 31 January 2019).

30. Karlsson, C. Researching Operations Management, 3rd ed.; Routledge: Abingdon, UK, 2010; ISBN 978-0-415-99056-1.

31. Meredith, J. Building operations management theory through case and field research. J. Oper. Manag. 1998, 16, 441-454. [CrossRef]

32. Coghlan, D.; Brannick, T. Doing Action Research in Your Own Organization, 4th ed.; SAGE Publications Ltd.: London, UK, 2014; ISBN 978-1-4462-7257-2.

33. Van de Ven, A.H.; Johnson, P.E. Knowledge for theory and practice. Acad. Manag. Rev. 2006, 31, $802-821$. [CrossRef]

34. Pagell, M.; Shevchenko, A. Why research in sustainable supply chain management should have no future. J. Supply Chain Manag. 2014, 50, 44-55. [CrossRef]

35. WWF Climate Savers. 2015. Available online: http:/ / climatesavers.org/volvo/ (accessed on 15 January 2016).

36. Bartunek, J.M.; Woodman, R.W. Beyond Lewin: Toward a temporal approximation of organization development and change. Annu. Rev. Organ. Psychol. Organ. Behav. 2015, 2, 157-182. [CrossRef]

37. Hall, N.P.; Roth, J. Non-energy benefits from commercial and industrial energy efficiency programs: Energy efficiency may not be the best story. In Proceedings of the 2003 International Energy Program Evaluation Conference, Seattle, WA, USA, 20-22 August 2003; pp. 689-702.

(C) 2019 by the authors. Licensee MDPI, Basel, Switzerland. This article is an open access article distributed under the terms and conditions of the Creative Commons Attribution (CC BY) license (http:/ / creativecommons.org/licenses/by/4.0/). 